\title{
Development of anthracycline-induced dilated cardiomyopathy due to mutation on LMNA gene in a breast cancer patient: a case report
}

\author{
Jock Chichaco Kuruc ${ }^{1,2}$, Armando A. Durant-Archibold ${ }^{1,3^{*}}$ (D) Jorge Motta ${ }^{1,4,5,6}$, K. S. Rao ${ }^{1}$, Barry Trachtenberg ${ }^{7}$, \\ Carlos Ramos ${ }^{3}$, Hongyu Wang ${ }^{8}$, David Gorenstein ${ }^{8}$, Fredrik Vannberg ${ }^{9}$ and King Jordan ${ }^{* *}$
}

\begin{abstract}
Background: Anthracyclines are highly effective anticancer medication prescribed for the treatment of breast cancer. Nevertheless, the use of anthracyclines as chemotherapeutic agents involves a risk for development of cardiac toxicity which may cause restrictive and dilated cardiomyopathy. Currently, genetic predisposition is not considered as a risk factor for cardiotoxicity associated to the use of anthracyclines.

Case presentation: We report the case of a 37-years old Panamanian female patient diagnosed with breast cancer who developed clinical signs of severe heart failure after treatment with doxorubicin. A diagnosis of anthracycline induced cardiomyopathy was made and treatment was initiated accordingly. A whole exome sequencing study performed to the patient showed the presence of a missense mutation in LMNA gene, which codifies for lamin A/C. Our results points to a correlation between the LMNA variant and the anthracycline cardiotoxicity developed by the woman. Improvement of the clinical symptoms and the left ventricle ejection fraction was observed after proper treatment.

Conclusions: This case report suggests for the first time a potential genetic predisposition for anthracyclines induced cardiomyopathy in patients with mutations in LMNA gene. Perhaps chemotherapies accelerate or deliver the "second-hit" in the development of DCM in patients with genetic mutations. More data is needed to understand the contribution of LMNA variants that predispose to DCM in patients receiving cardiotoxic therapies.
\end{abstract}

Keywords: Cardiotoxicity, Dilated cardiomyopathy, Antrhacyclines, LMNA gene, Breast cancer

\section{Background}

Anthracyclines, such as doxorubicin and epirubicin, are highly effective and frequently used antineoplastic drugs prescribed for a variety of malignancies, including breast cancer $[1,2]$. These drugs inhibit the enzyme topoisomerase II, leading to disruption in DNA replication and transcription, which in turn impedes multiplication of cancer cells. Furthermore, they promote the production of Reactive

\footnotetext{
*Correspondence: armando.durant@gmail.com; adurant@indicasat.org.pa; king.jordan@biology.gatech.edu

${ }^{1}$ Molecular Medicine Research Unit, Center for Biodiversity and Drug

Discovery, Institute of Scientific Research and High Technology Services (INDICASAT- AIP), Panama City, Panama

${ }^{9}$ School of Biological Sciences, Georgia Institute of Technology, Atlanta, GA, USA

Full list of author information is available at the end of the article
}

Oxygen Species (ROS) which damage proteins, DNA and cell membranes of the fastest-dividing human cancer cells [2]. Anthracycline-based chemotherapy for the treatment of breast cancer is very effective, reducing the annual mortality in women with breast cancer by $20-38 \%$; nevertheless, the increased risk of cardiotoxicity in patients from anthracycline use has been very well described and analyzed in the medical literature [1-3]. The use of anthracyclines as chemotherapeutic agents involves an evident risk for development of cardiac toxicity generating restrictive and dilated cardiomyopathy resulting in congestive heart failure in approximately $16-20 \%$ of the treated patients [4]. The current assumptions indicate that anthracycline-induced cardiomyopathy is the result of complex multifactorial processes affecting cardiomyocytes such as inhibition of protein and nucleic acid

(c) The Author(s). 2019 Open Access This article is distributed under the terms of the Creative Commons Attribution 4.0 International License (http://creativecommons.org/licenses/by/4.0/), which permits unrestricted use, distribution, and reproduction in any medium, provided you give appropriate credit to the original author(s) and the source, provide a link to the Creative Commons license, and indicate if changes were made. The Creative Commons Public Domain Dedication waiver (http://creativecommons.org/publicdomain/zero/1.0/) applies to the data made available in this article, unless otherwise stated. 
synthesis, the generation of ROS, through interactions with topoisomerase-II $\beta$ present in cardiomyocytes, changes in adrenergic function and adenylate cyclase, increased membrane lipid peroxidation, abnormalities in calcium ion handling, impairment of membrane binding, enzymatic activity and assembly of mitochondrial creatine kinase, induction of nitric oxide synthase enzyme, leading to nitric oxide and peroxynitrite and converse nitration/inactivation of myofibrillar creatine kinase or nitration/activation of metalloproteinases, accumulation of anthracyclines metabolites in the cardiomyocytes, and the development of apoptosis $[2,5]$. The main potential risk factors described for anthracycline-induced cardiotoxicity includes cumulative and individual anthracyclines dose, age extremes, female sex, previous history of cardiovascular disease, pulmonary disease, pregnancy, infection, reduced infusion time, concomitant radiation therapy, and concomitant cardiotoxic chemotherapies (e.g her-2 anatgonists) [2]. The damage upon the heart may occur months or years after chemotherapeutic treatment at or near usual maximum doses $[2,6,7]$. Although genome-wide association investigations performed have discovered correlations between anthracycline cardiotoxicity and specific genetic mutations, there is not currently enough evidence to recommend screening patients for variants to guide clinical decision-making for cancer patients.

Here we report the case of a breast cancer patient with a mutation in LMNA gene who developed dilated cardiomyopathy (DCM) after treatment with doxorubicin, suggesting a potential genetic predisposition for DCM in patients with mutations in this gene. As for as our knowledge, this is the first report that correlates mutations in $L M N A$ as a risk factor for the development of anthracycline-induced cardiomyopathy.

\section{Case presentation}

A 37-year-old Panamanian female patient without a preexisting medical history, was diagnosed with a stage IIIB mammary ductal carcinoma (cT4NOM0), positive estrogen receptors (ER-positive), negative progesterone receptors (PR-negative) in her right breast in 2013, for which she received four cycles of doxorubicin (cumulative dose $240 \mathrm{mg} / \mathrm{m}^{2}$ ) and cyclophosphamide from January to March 2013, followed by paclitaxel from April to June. An electrocardiogram (Fig. 1) and chest radiography done

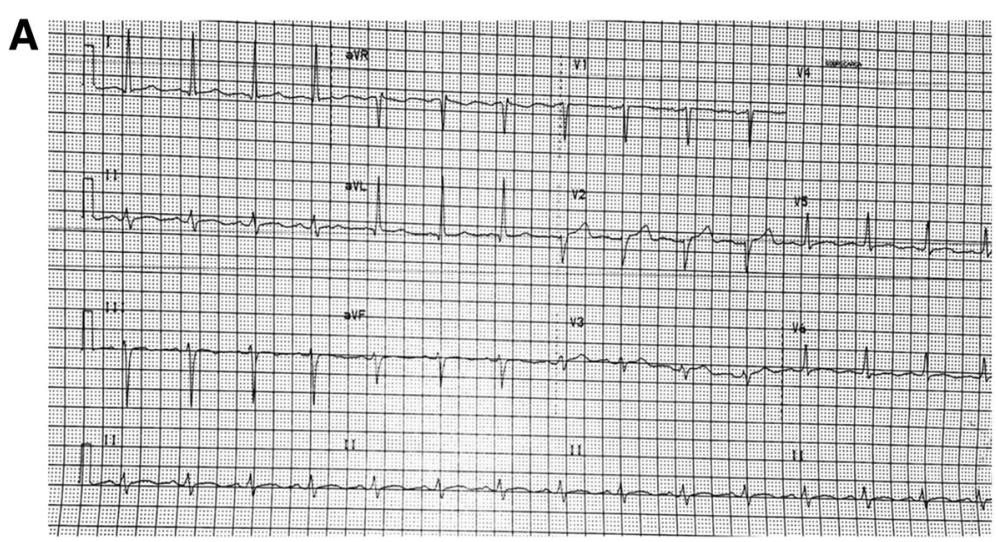

B

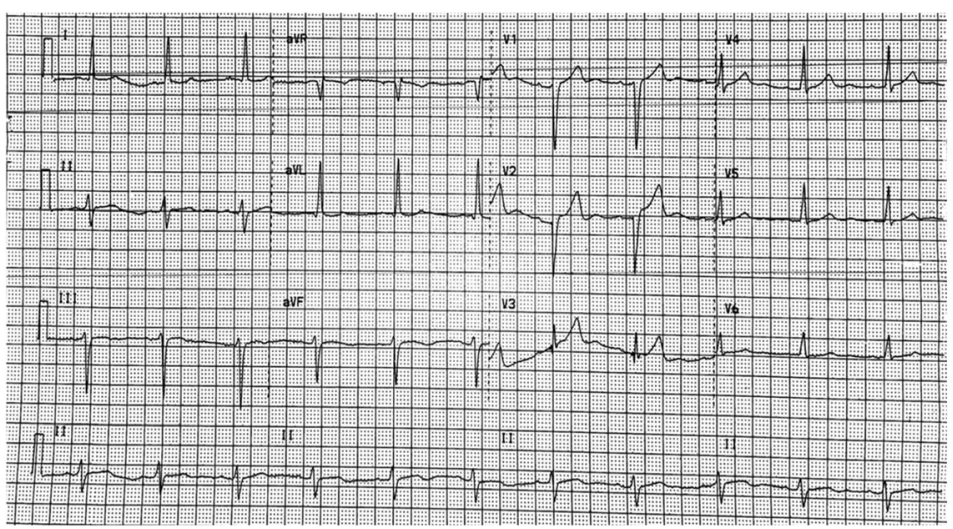

Fig. 1 Progressive changes observed on electrocardiograms obtained from the proband. The first electrocardiogram (ECG) obtained 6 months after the beginning of the chemotherapy reported inactivable electrical zones at V1 and V3 leads with a cardiac axis of $-17^{\circ}(\mathbf{a})$. The proband presented clinical signs of heart failure 48 months after treatment, an ECG at the time reported left anterior hemiblock and signs compatible with left cavities enlargement, cardiac axis $-46^{\circ}$ (b 
prior to chemotherapy revealed no cardiac alterations. In July 2013 the patient underwent mastectomy, with subsequent radiation therapy ( 45 Gy in 25 fractions).

Two years later, she was admitted to the hospital emergency department with 10 days history of orthopnea, swelling of her arms and legs, bendopnea, and fatigue. An echocardiogram was ordered, showing a reduced left ventricular systolic function (LVEF 25\%). The diagnosis of anthracyclines induced cardiomyopathy was established. She was treated with a beta-blocker, diuretics and antihypertensives. After two weeks, she showed a significant improvement of her symptoms, with a LVEF of $45 \%$. A year later, her 38-year-old brother was admitted to the hospital with a clinical presentation characterized by swelling of his legs, fatigue and minimum effort dyspnea, a left ventricular internal diameter in diastole (LVIDd) of $7.52 \mathrm{~cm}$, with a LVEF of $20 \%$. This clinical event prompted us to consider whether our patient had a genetic predisposition for DCM, and thus we performed a complete pedigree analysis of the proband (Fig. 2 and Additional file 1: Figure S1) that showed the presence of several DCM cases in the family.

In order to establish the genetic mutation responsible for the familial DCM, genomic DNA was extracted from whole-blood samples of the proband, and her brother, using a Masterpure DNA purification kit following the manufacturer's protocol, and untargeted whole exome sequencing (WES) assessment was performed. Briefly, DNA samples were amplified prior to exome library preparation by means of GenomiPhi V3 DNA Amplification Kit. Exome libraries of the selected individuals were prepared from amplified DNA using an Illumina Nextera Rapid Capture Exome kit (version 1.1, $37 \mathrm{Mb}$ ). Genomic DNA was then tagmented, and amplified using polymerase chain reaction amplification (PCR); regions of interest (exons) were captured by hybridization to specific probes followed by a cycle of PCR amplification. The sequencing step was performed on an Illumina HiSeq 2500 platform, targeting for $100 \mathrm{bp}$ pair-end reads, and a mean sequencing coverage average above $80 x$. The clinically relevant variant was subsequently confirmed by means of Sanger sequencing. The genetic investigations revealed the presence of a LMNA-p.Arg190Trp (NM_170707.3:c.568C > T) missense variant.

\section{Discussion and conclusions}

We present the case of a patient with breast cancer with a mutation in the LMNA gene who developed cardiomyopathy after treatment with anthracycline. LMNA codifies for lamin $\mathrm{A} / \mathrm{C}$ protein, which has a diversity of roles in the body, such as nuclear structure support, cell signaling pathway mediation, chromatin organization and DNA repair. Mutations in LMNA have been associated with the development of variety of pathologies such as LMNA cardiomyopathy [8, 9]. Variants in $L M N A$ gene are responsible for around $6-8 \%$ of the reported cases of fDCM with conduction-system disease $[10,11]$. The $L M N A$ variant identified in the proband, LMNA-p.Arg190Trp (NM_170707.3:c.568C > T) which alters the helical rod domain of the protein, has been described earlier and implicated in acute types of familial DCM with, and without, conduction-system disease [12-16]. Previous case series have been reported on patients who developed anthracycline cardiomyopathy and were subsequently found to have genetic mutations known to be associated with DCM, such as MYH7 ( $\beta$-myosin heavy chain) and TTN (titin striated muscle protein) $[17,18]$. To our knowledge, this is the first case report of a patient with anthracycline-induced cardiotioxicity because of a $L M N A$ gene mutation. Despite

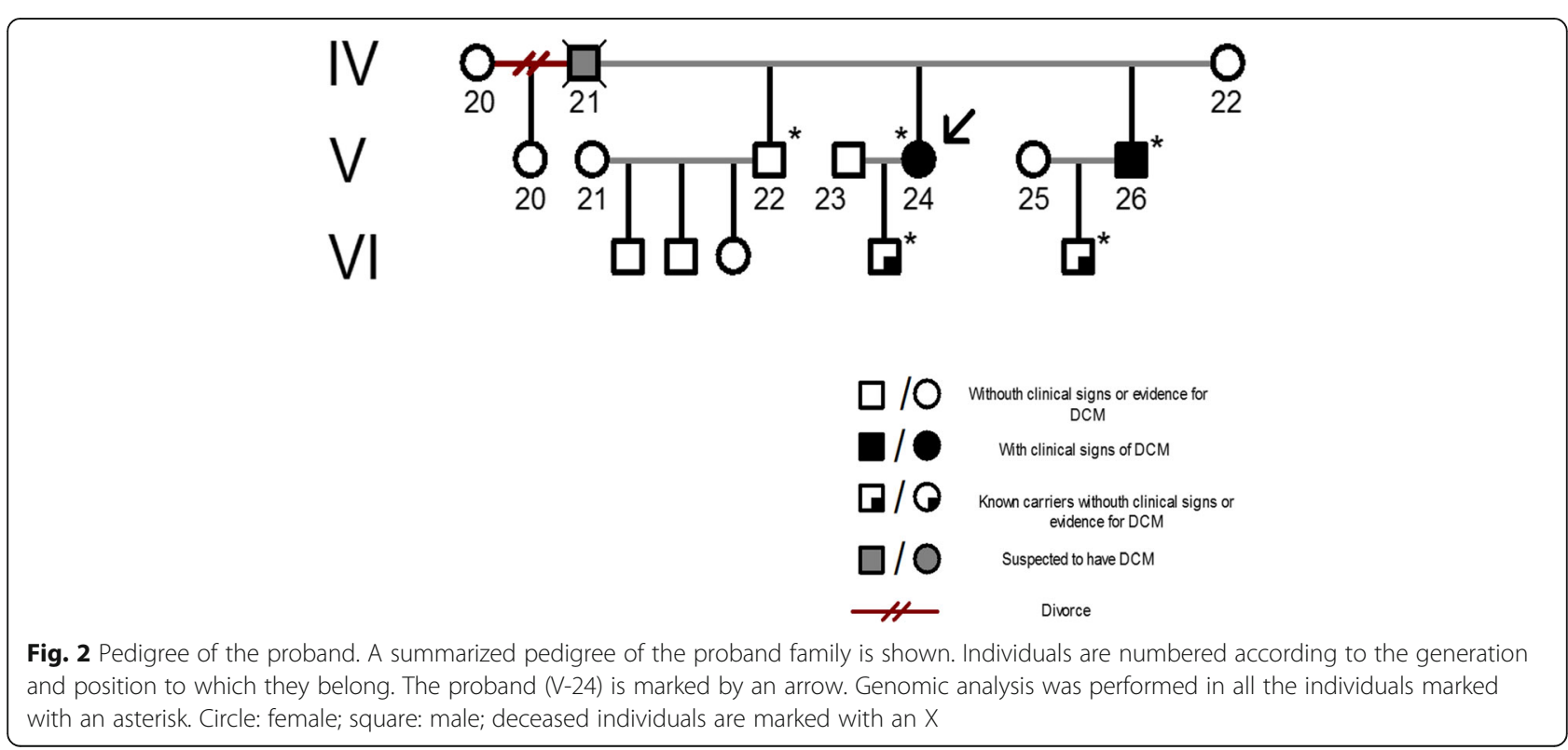


the explosion of targeted chemotherapies and immunotherapies, the use of anthracyclines remains common as they are highly effective chemotherapies for many different types of cancers that afflict both adults and children [2, 18, 19]. As shown in our case, for cancer patients bearing the mutation highlighted in LMNA gene, treatment with anthracyclines can be considered a risk factor for cardiotoxicity and early development of dilated cardiomyopathy due to their genetic predisposition. More data is needed to understand the contribution and frequency of mutations (such as LMNA) that predispose to DCM in patients receiving potentially cardiotoxic therapies such as anthracyclines. While penetrance is incomplete in DCM genes, perhaps chemotherapies accelerate or deliver the "second-hit" in the development of DCM in patients with genetic mutations. One can envision, if further evidence supports this hypothesis, that we could truly offer precision medicine by screening patients prior to starting chemotherapy for genetic mutations that would increase their risk of developing heart failure.

\section{Additional file}

Additional file 1: Figure S1. Support Information. Complete Pedigree of the proband family. Displays the complete pedigree of the proband family. Individuals are numbered according to the generation and position to which they belong. The distribution of the cases suggest the presence of an autosomal dominant disease. Circle: female; square: male; deceased individuals are marked with an X. (JPG 514 kb)

\section{Abbreviations}

DCM: Dilated cardiomyopathy; LVEF: Left ventricular systolic function; LVIDd: Left ventricular internal diameter in diastole; MYH7: $\beta$-Myosin heavy chain; PCR: Polymerase chain reaction; TTN: Titin striated muscle protein; WES: Whole exome sequencing

\section{Acknowledgments}

We are obliged to the patients who participated in this study. AAD-A and KSR gratefully acknowledge the support received through the National System of Research Awards (SNI) of Panama. We acknowledge Dr. Mahabir P. Gupta for comments that greatly improved the manuscript; Anna Melhado and Yamibel Diaz for technical support.

\section{Authors' contributions}

JCK: writing, data collection, analysis and interpretation of data. JM: patient's attention, idea, critical revision. BT: analysis and interpretation of patient's data, writing. AAD-A: idea, design, writing, project management, analysis and interpretation of data. KJ: writing, analysis of data. FV: data collection, analysis and interpretation of data. KSR: idea, critical revision. CR, HW, DG: critical revision. All authors read and approved the final manuscript.

\section{Funding}

This study was supported by grant from the National Secretariat of Science, Technology and Innovation of Panama (ECS11-002).

\section{Availability of data and materials}

All relevant data supporting this research are contained within the article.

\section{Ethics approval and consent to participate}

All procedures performed in this research were in accordance with the ethical standards of the Panamanian Bioethics Committee, and with the 1964 Helsinki declaration. All participants in this report voluntarily agreed to participate and signed written consent.

\section{Consent for publication}

Written informed consent was obtained from the patient for publication of this case report and any accompanying images.

\section{Competing interests}

The authors declare they have no competing interests.

\section{Author details}

${ }^{1}$ Molecular Medicine Research Unit, Center for Biodiversity and Drug Discovery, Institute of Scientific Research and High Technology Services (INDICASAT- AIP), Panama City, Panama. ${ }^{2}$ Acharya Nagarjuna University, Nagarjuna Nagar, India. ${ }^{3}$ College of Natural, Exact Science and Technology, Universidad de Panama, Panama City, Panama. ${ }^{4}$ National Secretariat for Science, Technology and Innovation, Panama City, Panama. ${ }^{5}$ Punta Pacifica Hospital, Panama City, Panama. ${ }^{6}$ Gorgas Memorial Institute for Health Studies, Panama City, Panama. ${ }^{7}$ Department of Cardiology, Houston Methodist DeBakey Heart and Vascular Center, Houston, TX, USA. ${ }^{8}$ Brown Foundation Institute of Molecular Medicine, McGovern Medical School, The University of Texas Health Science Center at Houston, Houston, TX, USA. ${ }^{9}$ School of Biological Sciences, Georgia Institute of Technology, Atlanta, GA, USA.

Received: 27 February 2019 Accepted: 10 July 2019

Published online: 16 July 2019

\section{References}

1. Greene J, Hennessy B. The role of anthracyclines in the treatment of early breast cancer. J Oncol Pharm Pract. 2015;21:201-12.

2. Aminkeng F, Ross CJ, Rassekh SR, Hwang S, Rieder MJ, Bhavsar AP, Smith A, Sanatani S, Gelmon KA, Bernstein D, Hayden MR, Amstutz U, Carleton BC. Recommendations for genetic testing to reduce the incidence of anthracycline-induced cardiotoxicity. Br J Clin Pharmacol. 2016;82:683-95.

3. Turner N, Biganzoli L, Di Leo A. Continued value of adjuvant anthracyclines as treatment for early breast cancer. Lancet Oncol. 2015;16:e362-9.

4. Hershman DL, Shao T. Anthracycline cardiotoxicity after breast cancer treatment. Oncology (Williston Park). 2009;23:227-34.

5. Minotti G, Menna P, Salvatorelli E, Cairo G, Gianni L. Anthracyclines: molecular advances and pharmacologic developments in antitumor activity and cardiotoxicity. Pharmacol Rev. 2004;56:185-229.

6. Kremer LC, van Dalen EC, Offringa M, Voûte PA. Frequency and risk factors of anthracycline-induced clinical heart failure in children: a systematic review. Ann Oncol. 2002;13:503-12.

7. Barry E, Alvarez JA, Scully RE, Miller TL, Lipshultz SE. Anthracycline-induced cardiotoxicity: course, pathophysiology, prevention and management. Expert Opin Pharmacother. 2007:8:1039-58.

8. Wang X, Zabell A, Koh W, WilsonTang WH. Lamin a/C cardiomyopathies: current understanding and novel treatment strategies. Cur Treat Options Cardio Med. 2017:19:21.

9. Al-Saaidi RA, Rasmussen TB, Birkler RID, Palmfeldt J, Beqqali A, Pinto YM, Nissen PH, Baandrup U, Mølgaard H, Hey TM, Eiskjær H, Bross P, Mogensen J. The clinical outcome of LMNA missense mutations appears to be associated with the amount of mutated protein in the nuclear envelope. Eur J Heart Fail. 2018:10:1404-12.

10. Taylor MR, Fain PR, Sinagra G, Robinson ML, Robertson AD, Carniel E, Di Lenarda A, Bohlmeyer TJ, Ferguson DA, Brodsky GL, Boucek MM, Lascor J, Moss AC, Li WL, Stetler GL, Muntoni F, Bristow MR, Mestroni L. Natural history of dilated cardiomyopathy due to Lamin a/C gene mutations. J Am Coll Cardiol. 2003;41:771-80.

11. Schreiber KH, Kennedy BK. When lamins go bad: nuclear structure and disease. Cell. 2013;152:1365-75.

12. Song K, Dube M, Lim J, Hwang I, Lee I, Kim JJ. Lamin a/C mutations associated with familial and sporadic cases of dilated cardiomyopathies in Koreans. Exp Mol Med. 2007:39:114-20.

13. Anan R, Niimura H, Sasaki T, Seidman JG, Seidman CE, Minagoe S, Tei C. A novel Lamin a/C missense mutation in a family with autosomal dominant dilated cardiomyopathy with conduction abnormalities. J Am Coll Cardiol. 2002;39:s136.

14. Arbustini E, Pilotto A, Repetto A, Grasso M, Negri A, Diegoli M, Campana C, Scelsi L, Baldini E, Gavazzi A, Tavazzi L. Autosomal dominant dilated cardiomyopathy with atrioventricular block: a Lamin a/C defect-related disease. J Am Coll Cardiol. 2002;39:981-90. 
15. Hermida-Prieto M, Monserrat L, Castro-Beiras A, Laredo R, Soler R, Peteiro J, Rodriguez E, Bouzas B, Alvarez N, Muniz J, Crespo-Leiro M. Familial dilated cardiomyopathy and isolated left ventricular noncompaction associated with Lamin a/C gene mutations. Am J Cardiol. 2004:94:50-4.

16. Sylvius $\mathrm{N}$, Bilinska ZT, Veinot JP, Fidzianska A, Bolongo PM, Poon S, Mckeown P, Davies RA, Chan KL, Tang AS, Dyack S, Grzybowski J, Ruzyllo W, McBride $H$, Tesson F. In vivo and in vitro examination of the functional significances of novel Lamin gene mutations in heart failure patients. J Med Genet. 2005:42:639-47.

17. Wasielewski M. Van Spaendonck-Zwarts KY, Westerink ND, Jongbloed JD, Postma a, Gietema JA, van Tintelen JP, van den berg MP. Potential genetic predisposition for anthracycline-associated cardiomyopathy in families with dilated cardiomyopathy. Open Heart. 2014;1:e000116.

18. Linschoten M, Teske AJ, Baas AF, Vink A, Dooijes D, Baars HF, Asselbergs FW. Truncating titin (TTN) variants in chemotherapy-induced cardiomyopathy. J Card Fail. 2017;23:476-9.

19. Young AC, Mercer B, Perren TJ, Dodwell D. Anthracycline-induced cardiomyopathy in siblings with early breast cancer. Ann Oncol. 2011;22:1692.

\section{Publisher's Note}

Springer Nature remains neutral with regard to jurisdictional claims in published maps and institutional affiliations.

Ready to submit your research? Choose BMC and benefit from:

- fast, convenient online submission

- thorough peer review by experienced researchers in your field

- rapid publication on acceptance

- support for research data, including large and complex data types

- gold Open Access which fosters wider collaboration and increased citations

- maximum visibility for your research: over $100 \mathrm{M}$ website views per year

At BMC, research is always in progress.

Learn more biomedcentral.com/submissions 